\title{
Fibrous boron carbide prepared from electrospun condensed boric acid-poly(vinyl alcohol) product fibers
}

\author{
Masaki KAKIAGE ${ }^{1,2, \dagger,}$, Taiju KOBAYASHI ${ }^{3}$ and Kazuma YABUYA ${ }^{3}$ \\ ${ }^{1}$ Institute for Fiber Engineering, Shinshu University (IFES), Interdisciplinary Cluster for Cutting Edge Research (ICCER), \\ Shinshu University, 3-15-1 Tokida, Ueda, Nagano 386-8567, Japan \\ ${ }^{2}$ Division of Molecular Science, Graduate School of Science and Technology, Gunma University, \\ 1-5-1 Tenjin-cho, Kiryu, Gunma 376-8515, Japan \\ ${ }^{3}$ Department of Textile Science and Technology, Graduate School of Science and Technology, Shinshu University, \\ 3-15-1 Tokida, Ueda, Nagano 386-8567, Japan
}

\begin{abstract}
Fibrous crystalline boron carbide $\left(\mathrm{B}_{4} \mathrm{C}\right)$ was fabricated by carbothermal reduction starting from electrospun condensed boric acid $\left(\mathrm{H}_{3} \mathrm{BO}_{3}\right)$-poly(vinyl alcohol) (PVA) product fibers. The addition of hydrochloric acid to a $\mathrm{H}_{3} \mathrm{BO}_{3}-\mathrm{PVA} /$ dimethyl sulfoxide solution resulted in electrospinnability of the solution; thus, condensed $\mathrm{H}_{3} \mathrm{BO}_{3}$ PVA product fibers were prepared by electrospinning. The fibrous $\mathrm{B}_{4} \mathrm{C}$ precursor was prepared by the thermal decomposition of the electrospun $\mathrm{H}_{3} \mathrm{BO}_{3}$-PVA product fibers in air. The fibrous $\mathrm{B}_{4} \mathrm{C}$ was obtained by heat treatment of the fibrous precursor at $1400^{\circ} \mathrm{C}$ in an Ar flow. The structure of fibers in fibrous $\mathrm{B}_{4} \mathrm{C}$ consisted of connected particles.

(O2020 The Ceramic Society of Japan. All rights reserved.
\end{abstract}

Key-words: Boron carbide $\left(\mathrm{B}_{4} \mathrm{C}\right)$, Fibrous structure, Precursor, Poly(vinyl alcohol) (PVA), Electrospinning Carbothermal reduction

[Received December 17, 2019; Accepted February 5, 2020]

Fibrous ceramics are attractive for use as a highly anisotropic filler for ceramic/ceramic or ceramic/polymer composite materials. Boron carbide $\left(\mathrm{B}_{4} \mathrm{C}\right)$ is an important nonoxide ceramic with attractive properties (high melting temperature, low specific weight, excellent hardness, and high chemical stability) and superior functions (high thermal neutron absorption cross section and excellent hightemperature thermoelectric properties). ${ }^{1)}$ Hence, fibrous $\mathrm{B}_{4} \mathrm{C}$ is expected to be used in a nonwoven structure and as reinforcing fiber. The formation of fibrous $\mathrm{B}_{4} \mathrm{C}$ using specialized techniques and/or raw materials was previously reported. ${ }^{2-6)}$ We successfully fabricated fibrous crystalline $\mathrm{B}_{4} \mathrm{C}$ consisting of connected particles by carbothermal reduction [Eq. (1)] via electrospinning. ${ }^{7)}$

$$
2 \mathrm{~B}_{2} \mathrm{O}_{3}+7 \mathrm{C} \rightarrow \mathrm{B}_{4} \mathrm{C}+6 \mathrm{CO}
$$

This is an evolutionary method of our low-temperature synthesis method of boride powders by carbothermal reduction, ${ }^{8)-18)}$ and is a preferred approach because carbothermal reduction is the conventional manufacturing process for $\mathrm{B}_{4} \mathrm{C}$. In our method of fabricating fibrous $\mathrm{B}_{4} \mathrm{C},{ }^{7}$ the fibrous $\mathrm{B}_{4} \mathrm{C}$ precursor consisting of boron oxide $\left(\mathrm{B}_{2} \mathrm{O}_{3}\right)$ particles and a carbon matrix is prepared by the

\footnotetext{
Corresponding author: M. Kakiage; E-mail: kakiage@ gunma-u.ac.jp

* Present address (M. Kakiage): Gunma University
}

thermal decomposition of electrospun condensed boric acid $\left(\mathrm{H}_{3} \mathrm{BO}_{3}\right)$-poly(vinyl alcohol) (PVA) product fibers in air. A spinning solution, $\mathrm{H}_{3} \mathrm{BO}_{3}-\mathrm{PVA} /$ dimethyl sulfoxide (DMSO) solution, had no electrospinnability owing to its high viscosity, and thus the blending of glycerin, as a plasticizer, in the solution is needed to enable electrospinning. ${ }^{7)}$ In this study, we attempted to prepare condensed $\mathrm{H}_{3} \mathrm{BO}_{3}$-PVA product fibers by electrospinning without a plasticizer.

PVA (PVA-117) was supplied by Kuraray Co., Ltd., Japan. $\mathrm{H}_{3} \mathrm{BO}_{3}(99.5 \%)$, DMSO $(99.0 \%)$, and hydrochloric acid $(\mathrm{HCl}, 1 \mathrm{~mol} / \mathrm{L})$ were purchased from Wako Pure Chemical Industries, Ltd., Japan. These materials were used as received. PVA was dissolved in DMSO ( $5 \mathrm{wt} \%)$ by stirring and heating at $120^{\circ} \mathrm{C}$ for $1 \mathrm{~h}$, followed by slow cooling at room temperature (RT). $\mathrm{HCl}$ was added to the PVA/DMSO solution (5-15 wt\% relative to the PVA/ DMSO solution), and then $\mathrm{H}_{3} \mathrm{BO}_{3}$ was added, followed by stirring at RT for $1 \mathrm{~h}$. The above-mentioned processes were performed in a closed beaker. The condensed $\mathrm{H}_{3} \mathrm{BO}_{3}$-PVA product fibers were prepared by electrospinning of the $\mathrm{H}_{3} \mathrm{BO}_{3}$-PVA/DMSO solution. The obtained solution was electrospun at a fixed voltage and flow rate of $20 \mathrm{kV}$ and $2.5 \mathrm{~mL} / \mathrm{h}$, respectively. The inner diameter of the nozzle (stainless-steel needle) and the distance between the needle tip and the rotating collector were $0.50 \mathrm{~mm}$ and $15 \mathrm{~cm}$, respectively. The collector, which was covered with 

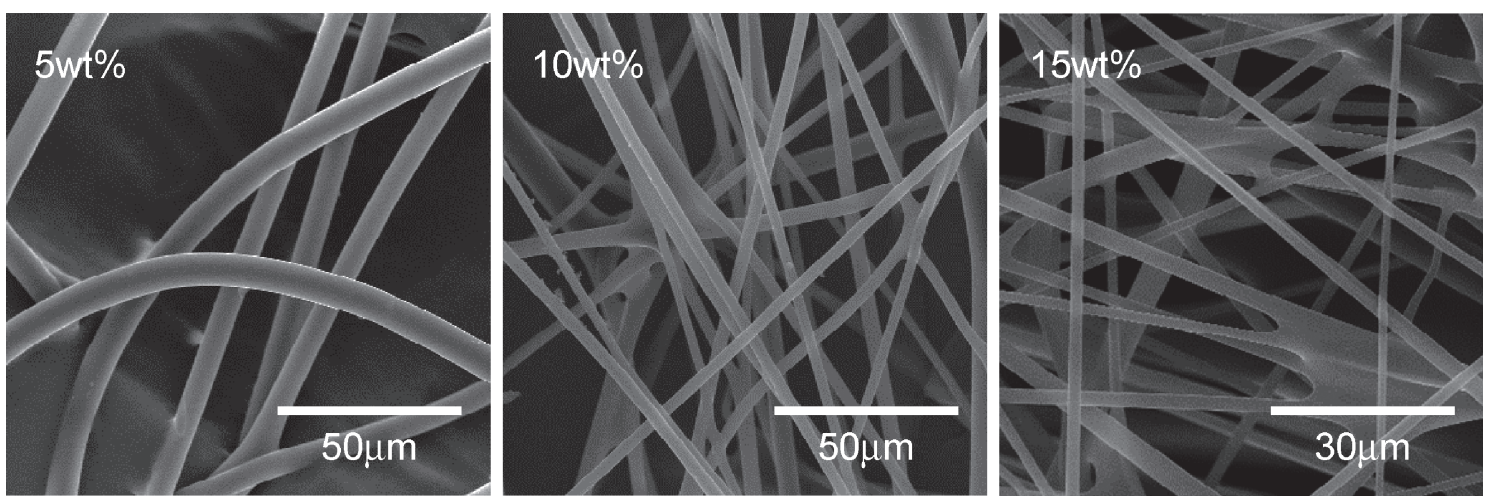

Fig. 1. FE-SEM images of condensed $\mathrm{H}_{3} \mathrm{BO}_{3}$-PVA product fibers prepared with various amounts of $\mathrm{HCl}$.

aluminum foil, was rotated at a speed of $20 \mathrm{~m} / \mathrm{min}$. The temperature throughout the process was $45^{\circ} \mathrm{C}$. The obtained electrospun condensed $\mathrm{H}_{3} \mathrm{BO}_{3}$-PVA product fibers were peeled off from the aluminum foil, dried at $120^{\circ} \mathrm{C}$ for $12 \mathrm{~h}$ in vacuum, and thermally decomposed at $580^{\circ} \mathrm{C}$ for $2 \mathrm{~h}$ in air. A fibrous $\mathrm{B}_{4} \mathrm{C}$ precursor obtained by the thermal decomposition of the condensed product fibers in air was placed in a graphite boat and heated at $1400^{\circ} \mathrm{C}$ for $5 \mathrm{~h}$ in an Ar flow $(200 \mathrm{~mL} / \mathrm{min})$ at a heating rate of $10^{\circ} \mathrm{C} / \mathrm{min}$.

$\mathrm{HCl}$ was used to decrease the viscosity of the spinning solution because acid weakens the interaction between $\mathrm{H}_{3} \mathrm{BO}_{3}$ and PVA. The $\mathrm{H}_{3} \mathrm{BO}_{3}$-PVA/DMSO solution without $\mathrm{HCl}$ was a heterogeneous solution including aggregates and had no electrospinnability. The homogeneous solution was prepared by adding $\mathrm{HCl}$. The viscosity of the $\mathrm{H}_{3} \mathrm{BO}_{3}$-PVA/DMSO solution decreased with increasing amount of $\mathrm{HCl}$, resulting in the electrospinnability of the solution, probably because of the moderate degradation of borate ester (B-O-C) bonds between $\mathrm{H}_{3} \mathrm{BO}_{3}$ and PVA. Figure 1 shows field-emission scanning electron microscope (FE-SEM) images of the electrospun fibers prepared from $\mathrm{H}_{3} \mathrm{BO}_{3}$-PVA/DMSO solutions with different amounts of $\mathrm{HCl}$. The formation of $\mathrm{B}-\mathrm{O}-\mathrm{C}$ bonds in the electrospun fibers was identified by the thermogravimetric measurements and attenuated total reflectance Fourier transform infrared measurements, indicating the formation of condensed $\mathrm{H}_{3} \mathrm{BO}_{3}$-PVA product fibers. The electrospun fibers prepared from the $\mathrm{H}_{3} \mathrm{BO}_{3}$-PVA/DMSO solution with $5 \mathrm{wt} \% \mathrm{HCl}$ had an inhomogeneous structure owing to its higher solution viscosity. Fiber diameter decreased with increasing amount of $\mathrm{HCl}$ owing to decreasing solution viscosity. Figure 2(a) shows a photograph of the obtained fibrous $\mathrm{B}_{4} \mathrm{C}$ precursor prepared by the thermal decomposition of the electrospun condensed $\mathrm{H}_{3} \mathrm{BO}_{3}$-PVA product fibers $(10 \mathrm{wt} \% \mathrm{HCl})$ in air. The precursor having a nonwoven structure was obtained. The fiber in the fibrous precursor consisted of nanosize $\mathrm{B}_{2} \mathrm{O}_{3}$ particles and a fibrous carbon matrix [Fig. 2(b)], similarly to that prepared using the $\mathrm{H}_{3} \mathrm{BO}_{3}$-PVA/DMSO solution with glycerin. ${ }^{7}$ This $\mathrm{B}_{2} \mathrm{O}_{3} /$ carbon structure is the characteristic morphology of the precursor prepared from a condensed $\mathrm{H}_{3} \mathrm{BO}_{3}$ PVA product. ${ }^{9), 12), 17)}$ Thus, the addition of $\mathrm{HCl}$ to the spinning solution does not affect the precursor structure, i.e.,
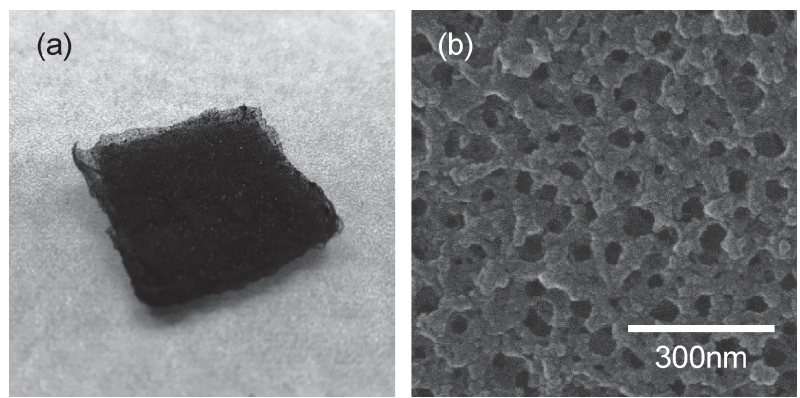

Fig. 2. (a) Photograph of fibrous $\mathrm{B}_{4} \mathrm{C}$ precursor prepared by thermal decomposition of electrospun condensed $\mathrm{H}_{3} \mathrm{BO}_{3}$-PVA product fibers $(10 \mathrm{wt} \% \mathrm{HCl})$ in air. (b) FE-SEM image of fibrous $\mathrm{B}_{4} \mathrm{C}$ precursor after removal of $\mathrm{B}_{2} \mathrm{O}_{3}$ by washing in hot water, leaving the carbon structure (pores where $\mathrm{B}_{2} \mathrm{O}_{3}$ previously existed).

the obtained fibrous $\mathrm{B}_{4} \mathrm{C}$ precursor has higher reactivity. ${ }^{17)}$ Consequently, the fibrous $\mathrm{B}_{4} \mathrm{C}$ precursor was prepared from the electrospun condensed $\mathrm{H}_{3} \mathrm{BO}_{3}$-PVA product fibers. In contrast, the fibrous precursor prepared using the $\mathrm{H}_{3} \mathrm{BO}_{3}$-PVA/DMSO solution with $15 \mathrm{wt} \% \mathrm{HCl}$ had an inhomogeneous $\mathrm{B}_{2} \mathrm{O}_{3} /$ carbon structure owing to excess weakening of the interaction between $\mathrm{H}_{3} \mathrm{BO}_{3}$ and PVA in the solution.

Figure 3 shows the X-ray diffraction (XRD) pattern of the product obtained from the fibrous $\mathrm{B}_{4} \mathrm{C}$ precursor prepared using the $\mathrm{H}_{3} \mathrm{BO}_{3}$-PVA/DMSO solution with 10 wt $\% \mathrm{HCl}$ after heat treatment at $1400^{\circ} \mathrm{C}$ for $5 \mathrm{~h}$ in an $\mathrm{Ar}$ flow. Peaks corresponding to a rhombohedral $\mathrm{B}_{4} \mathrm{C}$ crystal were observed, indicating that crystalline $\mathrm{B}_{4} \mathrm{C}$ with little free carbon was synthesized. The obtained product had the fibrous structure [Fig. 4(a)]. Consequently, fibrous crystalline $\mathrm{B}_{4} \mathrm{C}$ was formed from the electrospun condensed $\mathrm{H}_{3} \mathrm{BO}_{3}$-PVA product fibers. The structure of fibers in the fibrous $\mathrm{B}_{4} \mathrm{C}$ consisted of connected microparticles [Fig. 4(b)], in which the morphology was similar to that of $\mathrm{B}_{4} \mathrm{C}$ particles obtained from a condensed $\mathrm{H}_{3} \mathrm{BO}_{3}$-PVA product. ${ }^{9), 12)}$ This structure was also observed for $\mathrm{B}_{4} \mathrm{C}$ fibers prepared from the electrospun condensed $\mathrm{H}_{3} \mathrm{BO}_{3}$ PVA product fibers with glycerin. ${ }^{7)}$ These results suggest that this structure is characteristic of $\mathrm{B}_{4} \mathrm{C}$ fibers prepared from condensed $\mathrm{H}_{3} \mathrm{BO}_{3}$-PVA product fibers. 


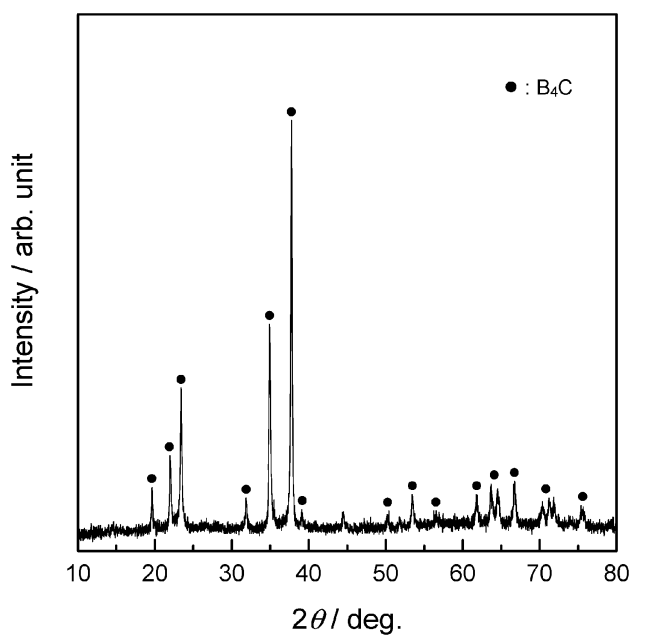

Fig. 3. XRD pattern of product obtained from fibrous precursor prepared using $\mathrm{H}_{3} \mathrm{BO}_{3}$-PVA/DMSO solution with $10 \mathrm{wt} \% \mathrm{HCl}$ after heat treatment at $1400^{\circ} \mathrm{C}$ for $5 \mathrm{~h}$ in an Ar flow.
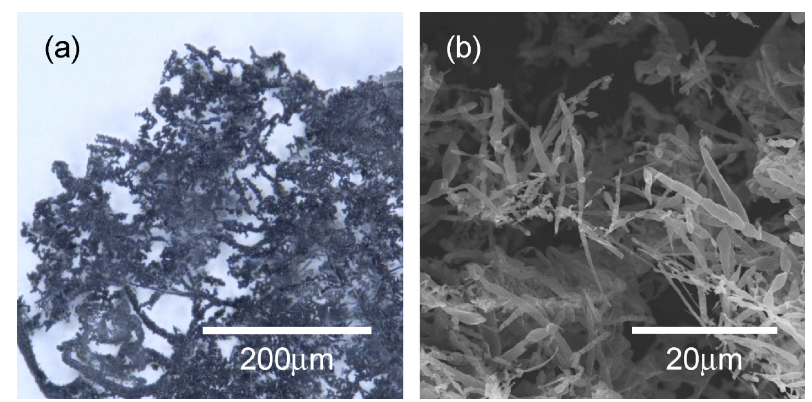

Fig. 4. (a) Digital microscopy and (b) SEM images of obtained fibrous $\mathrm{B}_{4} \mathrm{C}$.

In conclusion, we fabricated fibrous crystalline $\mathrm{B}_{4} \mathrm{C}$ by carbothermal reduction starting from electrospun condensed $\mathrm{H}_{3} \mathrm{BO}_{3}$-PVA product fibers. The electrospun condensed $\mathrm{H}_{3} \mathrm{BO}_{3}$-PVA product fibers were prepared from the $\mathrm{H}_{3} \mathrm{BO}_{3}$-PVA/DMSO solution with an adequate amount of $\mathrm{HCl}$ added to decrease the solution viscosity. The $\mathrm{B}_{4} \mathrm{C}$ precursor was prepared by the thermal decomposition of the electrospun condensed $\mathrm{H}_{3} \mathrm{BO}_{3}$-PVA product fibers in air and had the fibrous structure. Fibrous crystalline $\mathrm{B}_{4} \mathrm{C}$, in which the structure of fibers consisted of connected particles, was obtained by heat treatment of the fibrous $\mathrm{B}_{4} \mathrm{C}$ precursor at $1400{ }^{\circ} \mathrm{C}$ in an Ar flow.

Acknowledgement This work was partly supported by a Grant-in-Aid for Young Scientists (B) (JP16K21067) from the Japan Society for the Promotion of Science (JSPS).

\section{References}

1) F. Thévenot, J. Eur. Ceram. Soc., 6, 205-225 (1990).

2) D. Zhang, D. N. Mcilroy, Y. Geng and M. G. Norton, J. Mater. Sci. Lett., 18, 349-351 (1999).

3) M. J. Pender and L. G. Sneddon, Chem. Mater., 12, 280-283 (2000).

4) J. Wei, B. Jiang, Y. Li, C. Xu, D. Wu and B. Wei, J. Mater. Chem., 12, 3121-3124 (2002).

5) R. Ma and Y. Bando, Chem. Phys. Lett., 364, 314-317 (2002).

6) D. T. Welna, J. D. Bender, X. Wei, L. G. Sneddon and H. R. Allcock, Adv. Mater., 17, 859-862 (2005).

7) M. Kakiage and T. Kobayashi, Mater. Lett., 254, 158161 (2019).

8) M. Kakiage, N. Tahara, I. Yanase and H. Kobayashi, Mater. Lett., 65, 1839-1841 (2011).

9) M. Kakiage, N. Tahara, S. Yanagidani, I. Yanase and H. Kobayashi, J. Ceram. Soc. Jpn., 119, 422-425 (2011).

10) M. Kakiage, Y. Tominaga, I. Yanase and H. Kobayashi, Powder Technol., 221, 257-263 (2012).

11) M. Kakiage, N. Tahara, Y. Tominaga, S. Yanagidani, I. Yanase and H. Kobayashi, Key Eng. Mat., 534, 61-65 (2013).

12) M. Kakiage, N. Tahara, R. Watanabe, I. Yanase and H. Kobayashi, J. Ceram. Soc. Jpn., 121, 40-44 (2013).

13) N. Tahara, M. Kakiage, I. Yanase and H. Kobayashi, J. Alloy. Compd., 573, 58-64 (2013).

14) M. Kakiage, S. Shiomi, I. Yanase and H. Kobayashi, J. Am. Ceram. Soc., 98, 2724-2727 (2015).

15) M. Kakiage, T. Shoji and H. Kobayashi, J. Ceram. Soc. Jpn., 124, 13-17 (2016).

16) M. Kakiage, S. Shiomi, T. Ohashi and H. Kobayashi, Adv. Powder Technol., 29, 36-42 (2018).

17) M. Kakiage, J. Ceram. Soc. Jpn., 126, 602-608 (2018).

18) M. Kakiage, T. Ohashi, S. Shiomi and H. Kobayashi, Adv. Powder Technol., 30, 644-648 (2019). 